http://dx.doi.org/10.1590/1678-4162-9249

Arq. Bras. Med. Vet. Zootec., v.69, n.3, p.570-578, 2017

\title{
Caracterização do imunofenótipo das células envolvidas no processo fibrótico de fígados bovinos cronicamente infectados por Fasciola hepatica
}

\author{
[Immunophenotype characterization of the cells involved in the fibrotic process of bovine livers \\ chronically infected by Fasciola hepatica] \\ D.R. Sousa ${ }^{1}$, M.A. Silva ${ }^{1}$, J.L. Sequeira ${ }^{2}$, A.P. Madureira ${ }^{3}$, L.C. Nunes ${ }^{1 *}$ \\ ${ }^{1}$ Universidade Federal do Espírito Santo - Alegre, ES \\ ${ }^{2}$ Universidade Estadual Paulista - Unesp - Botucatu, SP \\ ${ }^{3}$ Universidade Federal de São João Del Rei - São João Del Rei, MG
}

\begin{abstract}
RESUMO
A fasciolose é uma doença parasitária causada por trematódeo do gênero Fasciola sp., que pode ocasionar fibrose hepática. Objetivou-se caracterizar o imunofenótipo das células que participam da fibrogênese de fígados bovinos frente à infecção por $F$. hepatica. Foram utilizados fragmentos dos lobos direito e esquerdo de 74 fígados bovinos com fasciolose. Os fragmentos foram submetidos a processamento histológico, coloração com tricrômico de Masson e imuno-histoquímica. Utilizaram-se análise estatística descritiva e teste de correlação de Spearmann com 5\% de probabilidade. Na classificação do grau de fibrose, observou-se prevalência do grau 1 , com associação positiva e significativa entre o grau de fibrose e o lobo hepático esquerdo $(\rho=0,41 ; \mathrm{P}<0,0001)$. Os imunofenótipos observados foram células estreladas hepáticas (CEHs) no parênquima e miofibroblastos (MFs) no espaço porta (EP). Não foram encontrados fibroblastos. Não houve correlação significativa entre o grau de fibrose e a quantidade de CEH nos lobos hepáticos, direito e esquerdo. Verificou-se aumento do número de estruturas portais, bem como do número de camadas circundando cada estrutura no $\mathrm{EP}$, contudo não houve influência de qualquer estrutura sobre o grau de fibrose hepática $(\mathrm{P}>0,05)$. Concluiu-se que as células CEH e os MFs participam da fibrogênese de fígados bovinos com fasciolose crônica.
\end{abstract}

Palavras-chaves: bovino, fasciolose, fibrogênese, imuno-histoquímica

\begin{abstract}
Fascioliasis is a parasitic disease caused by a fluke of the genus Fasciola sp., which can lead to end liver fibrosis. This study aimed to characterize the immunophenotype of cells that participate in the fibrogenesis of livers of cattle that face infection by F. hepatica. Fragments of the right and left lobes of 74 cattle livers with fascioliasis were used. The fragments were subjected to histological analysis, Masson's trichrome special stain, and immunohistochemistry. A descriptive statistical analysis was used, with a 5\% probability in Spearman correlation test. The classification of degree of fibrosis revealed prevalence of grade 1, with a positive and significant association between the degree of fibrosis and the left hepatic lobe $(\rho=0.41 ; p<0.0001)$. The observed immunophenotypes corresponded to hepatic stellate cells (HSCs) in the parenchyma and myofibroblasts (MFs) in the portal tract (PT). Fibroblasts were not found. There was no significant correlation between the degree of fibrosis and the amount of HSC in right and left hepatic lobes. There was an increase in the number of portal structures, as well as in the number of layers surrounding each structure of the PT, but there was no influence of any structure of the PT on the degree of liver fibrosis $(P>0.05)$. HSCs and MFs were concluded to play a role in the fibrogenesis of cattle livers with chronic fascioliasis.
\end{abstract}

Keywords: cattle, fascioliasis, fibrogenesis, immunohistochemistry

Recebido em 8 de setembro de 2016

Aceito em 30 de setembro de 2016

*Autor para correspondência (corresponding author)

E-mail: louisianecn@gmail.com 


\section{INTRODUÇÃO}

A fasciolose é uma doença parasitária causada por um trematoda Fasciola hepatica ou $F$. gigantica, que acomete os ductos biliares de várias espécies animais, inclusive os seres humanos, por isso é considerada um problema de saúde pública em muitas regiões tropicais e subtropicais (Marcos et al., 2007; Espinoza et al., 2010).

As perdas econômicos anuais geradas por essa infecção são de aproximadamente 50 milhões de dólares, resultado direto do aumento das condenações de fígados em matadouros frigoríficos e, de forma indireta, da diminuição da produtividade, sem estimar o impacto na saúde pública (Espinoza et al., 2010).

Desse modo, a fibrose hepática induzida por $F$. hepatica coloca essa infecção parasitária no contexto das doenças crônicas do fígado (Marcos et al., 2011). No fígado, independentemente da causa, as principais células responsáveis por produzir matriz extracelular são as células estreladas hepáticas (CEH), que, quando ativadas, adquirem um fenótipo de miofibroblastos (MF) (Friedman, 2008).

No entanto, estudos de cultura e in situ de fígados com fibrose forneceram evidências que indicam que miofibroblastos podem derivar de células que são distintas das CEHs (Cassiman et al., 2002; Uchio et al., 2002; Magness et al., 2004; Ramadori e Saile, 2004; Bataller e Brenner, 2005). Essas são denominadas como subpopulação de miofibroblastos portais (MFP), que incluem: células mesenquimais residentes, células semelhantes a fibroblastos chamados fibrócitos, MFs derivados de pequenos vasos portais, hepatócitos e fibrócitos derivadas de medula óssea (Lemoinne et al., 2013; Lemoinne et al., 2015).

Sabendo disso, Marcos et al. (2011) apontam que as informações disponíveis sobre a fibrose hepática induzida pela infecção por $F$. hepatica são escassas, tanto em animais quanto em seres humanos. Dessa forma, objetivou-se caracterizar o imunofenótipo das células que participam da fibrogênese de fígados bovinos frente à infecção por $F$. hepatica, buscando se obterem dados sobre a população celular e a distribuição da fibrose.

\section{MATERIAL E MÉTODOS}

Foram coletados 74 fígados de bovinos condenados por fasciolose, e um fígado normal para controle negativo, no matadouro frigorífico de Atílio Vivácqua, Espírito Santo, sob autorização e fiscalização do Instituto de Defesa Agropecuária e Florestal do Espírito Santo (IDAF-ES), no período de dezembro de 2010 a janeiro de 2011, seguindo as normas do Comitê de Ética no Uso de Animais (Ceua), número $055 / 2010$.

Os fígados foram avaliados e seccionados seguindo a divisão anatômica dos lobos direito e esquerdo. De cada lobo hepático foi coletado um fragmento medindo aproximadamente $2 \mathrm{~cm}^{3}$. Cada um deles foi fixado em formalina $10 \% \mathrm{e}$, em seguida, encaminhado ao Laboratório de Patologia Animal do Hospital Veterinário da Universidade Federal do Espírito Santo para processamento histológico de rotina, coloração com hematoxilina-eosina (HE) e tricrômico de Masson, para a avaliação e graduação da fibrose hepática segundo Oliveira et al. (2004).

As amostras, anteriormente classificadas no HE, foram desparafinizadas e hidratadas; em seguida, foram colocadas por 15 minutos em solução de água oxigenada 30 volumes diluídos em metanol, na proporção de 1:9, para bloqueio de peroxidases endógenas. Após esse procedimento, realizou-se lavagem em água destilada e recuperação de antigênica, com duas técnicas: uma com solução de citrato $10 \mathrm{mM}$ pH 6,0 , em autoclave microprocessada (Brastec $\AA$ Q290M22) a $120^{\circ} \mathrm{C}$ por 30 segundos, para os anticorpos antielastina e antifibroblasto, e a outra com solução de citrato $10 \mathrm{mM}$ pH 6,0 em panela de pressão microprocessada (Dako, S2800-1) a $125^{\circ} \mathrm{C}$ por 30 segundos, para o anticorpo anti- $\alpha$ SMA.

O material foi resfriado em temperatura ambiente por 20 minutos e lavado com solução tampão de TRIS pH 7,40 (TRIZMA BASE, Sigma Chemical CO., St. Louis MO., EUA), seguido de bloqueio de proteínas inespecíficas com solução de leite em pó Molico® a 3\%, durante uma hora.

Depois disso, o material foi lavado com solução tampão de TRIS e incubado com anticorpo primário em câmara úmida por 18 horas a $4^{\circ} \mathrm{C}$. As respectivas diluições dos anticorpos primários 
foram antielastina 1:100 (BA-4, Santa Cruz Biotechnology, Inc., Santa Cruz, CA), antifibroblasto 1:150 (TE7, Santa Cruz Biotechnology, Inc., Santa Cruz, CA) e antialpha smooth muscle actin 1:1250 (1A4 DakoCytomation). Os controles positivos foram cordão umbilical humano, artéria aorta bovina, tecido de granulação bovino, respectivamente para os anticorpos anti- $\alpha$-SMA, antielastina e antifibroblasto. Como controle negativo, foi omitido o anticorpo primário.

Após a incubação, o material foi lavado em solução de TRIS e, para a amplificação da reação, utilizou-se o sistema de detecção à base de polímeros NovoLink (Novocastra, 7280-K), incubado em temperatura ambiente com cada reagente por 30 minutos. Em seguida, as lâminas foram lavadas novamente com solução de TRIS e depois tratadas com solução de 3,3'diaminobenzidina (Liquid DAB, Dako K3466) durante cinco minutos, em temperatura ambiente. Seguiu-se lavagem em água corrente, depois água destilada e contracorado com hematoxilina de Harris, por 30 segundos; após, as lâminas foram lavadas em água corrente por 10 minutos e submetidas aos processos de desidratação e montagem em resina sintética.

A caracterização imuno-histoquímica das células que compõem a fibrose hepática, como células estreladas hepáticas (CEH), miofibroblastos (MFP) e fibroblastos (FB), foi baseada na morfologia de cada tipo celular e na marcação positiva dessas células para cada anticorpo utilizado, de acordo com Ramadori e Saile (2004). O MFP foi considerado positivo quando expressava $\alpha$-SMA e elastina, as $\mathrm{CEH}$ foram positivas para $\alpha$-SMA e negativas para elastina e o FB mostrou-se positivo para TE7.

As células positivamente marcadas pelos anticorpos propostos foram quantificadas em dois sítios distintos, a saber: espaço porta e parênquima. A quantificação no parênquima baseou-se na contagem de células imunopositivas em cinco campos lineares aleatórios, em microscopia de luz e objetiva de 20x. Após a avaliação, foi obtida a quantidade média de células por lobo hepático.
A análise imuno-histoquímica no espaço porta considerou a classificação da fibrose hepática proposta. Foi avaliado o número de células positivas por estruturas que compõem o espaço porta, como vênula (VP), arteríola (AP) e ducto biliar (DB), em cinco espaços porta aleatórios em cada lobo hepático. A análise estatística foi feita por análise descritiva, com os valores expressos em percentuais, e o teste de correlação de Spearmann foi realizado com $5 \%$ de probabilidade.

\section{RESULTADOS E DISCUSSÃO}

A classificação histológica da fibrose nos fígados infectados por $F$. hepatica revelou fibrose septal discreta em alguns espaços porta com infiltrado inflamatório linfo-histioplasmocitário leve na fibrose grau 1 (Fig.1A e 1B). Na fibrose grau 2, observou-se fibrose portal multifocal moderada com septos de tecido conjuntivo delgado e incompletos, além de proliferação moderada de ductos biliares e infiltrado linfohistioplasmocitário leve (Fig. 1C), e na fibrose grau 3 havia fibrose portal em ponte, com septos de tecido conjuntivo espessos (Fig. 1D), frequentemente ligando um espaço porta a outro, associado à proliferação de ductos multifocal intensa (Fig. 1E) e infiltrado linfohistioplasmocitário e eosinofílico multifocal moderado (Fig. 1F).

O resultado dos percentuais de fibrose por graus nos lobos hepáticos, dos fígados infectados por $F$. hepatica, encontra-se na Tab. 1. Observou-se uma associação positiva e significativa do grau de fibrose com o lobo hepático esquerdo $(\rho=0,41 ; P<0,0001)$.

A classificação proposta por Oliveira et al. (2004) tem sido mais utilizada por ter como vantagens o desenvolvimento de fibrose em $100 \%$ dos animais infectados, além de previsão cronológica com boa margem de confiança (Gomes et al., 2006). Mas, para bovinos, não há uma classificação bem estabelecida que avalie a progressão da fibrose com fasciolose. 


\section{Caracterização do imunofenótipo...}

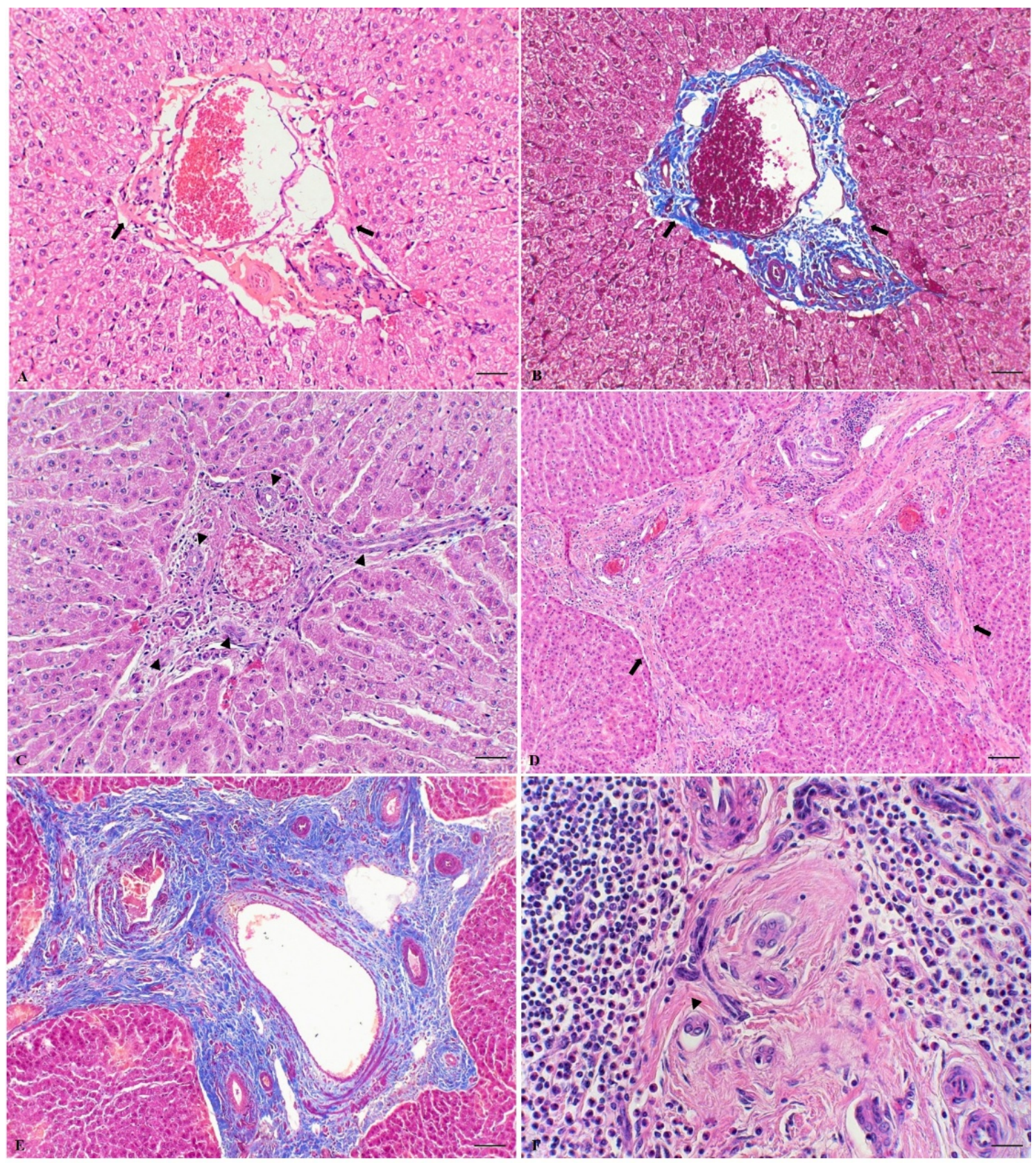

Figura 1. Fotomicrografia de fígado bovino com fasciolose. A) Fibrose grau 1, com discreta profileração de tecido conjuntivo ao redor das estruturas do espaço porta (seta), hematoxilina e eosina (HE), barra $6,4 \mu \mathrm{m}$. B) Fibrose grau 1, com tecido conjuntivo (azul) ao redor das estruturas do espaço porta (seta). Tricrômico de Masson, barra 6,4 $\mu \mathrm{m}$. C) Fibrose grau 2, com proliferação de ductos biliares (cabeça de seta) no espaço porta, proliferação de tecido conjuntivo moderado e infiltrado inflamatório leve, HE, barra $6,4 \mu \mathrm{m}$. D) Fibrose grau 3 apresentando infiltrado inflamatório multifocal moderado, proliferação de ducto bilar e septos de tecido conjuntivo espesso unindo um espaço porta ao outro (setas). HE, barra $14,5 \mu \mathrm{m}$. E) Fibrose grau 3, com espaço porta apresentando moderada quantidade de tecido conjuntivo (azul), arteríolas, vênulas, ductos biliares e infiltrado linfo-histioplasmocitário difuso leve. Tricrômico de Masson, barra 46,5 $\mu \mathrm{m}$. F) Fibrose grau 3 apresentando no espaço porta infiltrado linfohistioplasmocitário e eosinofílico difuso moderado e alguns ductos biliares, HE, barra $6,4 \mu \mathrm{m}$. 
Tabela 1. Porcentagem de fibrose por grau em cada lobo hepático nos fígados infectados por $F$. hepatica

\begin{tabular}{lccc}
\hline Fibrose & Grau 1 & Grau 2 & Grau 3 \\
\hline Lobo hepático direito & $90,5 \%(67 / 74)$ & $8,1 \%(6 / 74)$ & $1,4 \%(01 / 74)$ \\
Lobo hepático esquerdo & $55,4 \%(41 / 74)$ & $28,4 \%(21 / 74$ & $16,2 \%(12 / 74)$ \\
\hline
\end{tabular}

No presente estudo, houve maior prevalência de fibrose grau 1. No entanto, Marcos et al. (2007) verificaram maior prevalência de fibrose grau 3, enquanto Trivilin et al. (2014) encontraram fibrose grau 2. Tais divergências podem ser decorrentes de diferentes critérios morfológicos avaliados. Marcos et al. (2007) associaram a fibrose à carga parasitária, enquanto Trivilin et al. (2014) utilizaram como critério as alterações inflamatórias, ao passo que Oliveira et al. (2004) usaram a ocorrência de reinfecções. Ainda, devese considerar a resposta imune de cada hospedeiro frente à infecção, bem como às características bioquímicas do parasito (Meeusen e Piedrafita, 2003). Além disso, características epidemiológicas, como temperatura, pluviosidade, altitude dos locais, também podem influenciar a progressão da lesão hepática frente ao parasitismo (Alves et al., 2011).

O predomínio de fibrose no lobo hepático esquerdo foi observado por Shirai et al. (2006) e Tessele et al. (2013), respaldando os resultados obtidos neste estudo. Segundo Shirai et al. (2006), a presença de um único ramo de veia porta e de um único ducto biliar no lobo hepático esquerdo, paralelo com a superfície visceral e a superfície diafragmática, favorece a fibrose atrófica nesta área, agravando também pelo infiltrado inflamatório, o edema e a proliferação de tecido conjuntivo fibroso (Parola e Pinzan, 2009).

Em relação à caracterização do imunofenótipo das células que compõem a fibrose hepática, observou-se imunomarcação nas células estreladas hepáticas (CEHs) e em miofibroblastos portais (Fig. 2). A distribuição das CEHs foi observada unicamente no parênquima (Fig. 2C), localizadas entre os hepatócitos e os espaços de Disse, corroborando Kukolj et al. (2015), e os miofibroblastos foram observados nos EP. Resultados semelhantes foram relatados por Golbar et al. (2013).

Carpino et al. (2005) consideraram o anticorpo $\alpha$-SMA um marcador confiável de CEH ativadas, em seres humanos e em rato. Uchio et al. (2002), no entanto, relataram que nenhum marcador permite discriminar totalmente os $\mathrm{MFs}$ das $\mathrm{CEH}$ ativadas, na fase de miofibroblastos. Em concordância a isso, Cassiman et al. (2002) e Ramadori e Saile (2004) descreveram que os MFs de vasos e os FBP podem expressar essa proteína, o que revela a heterogenicidade do miofibroblastos hepáticos. A fim de diferenciar MFs de vasos de FBP presente no EP, utilizou-se o anticorpo TE7, contudo não houve imunomarcação nas amostras avaliadas.

A ausência de FB nas amostras avaliadas pode ser decorrente da ativação dessas células para miofibroblastos (Libbrecht et al., 2002; Uchio et al., 2002; Asahina et al., 2009). Kinnman e Housset (2002) relataram que obstruções de ductos biliares ativam os FBP em MFPs. A presença de lesão e/ou de células inflamatórias, os FB são estimulados por fator transformador de crescimento (TGF- $\beta 1$ ) e por fator de crescimento derivado de plaquetas e sofrem transdiferenciação para MFP (Safadi e Friedman, 2002; Bataller e Brenner, 2005; Gressner e Weiskirchen, 2006).

Estudos em fígados com fasciolose crônica indicaram que existe associação entre a intensidade da infecção e a progressão da fibrose em diversos modelos animais (Marcos et al., 2007). Golbar et al. (2013) e Kukolj et al. (2015) demostraram que a intensidade de expressão de $\alpha$-SMA nas CEH aumenta com a progressão da fibrose, em fígados bovinos e ovinos infectados por F. hepatica. 

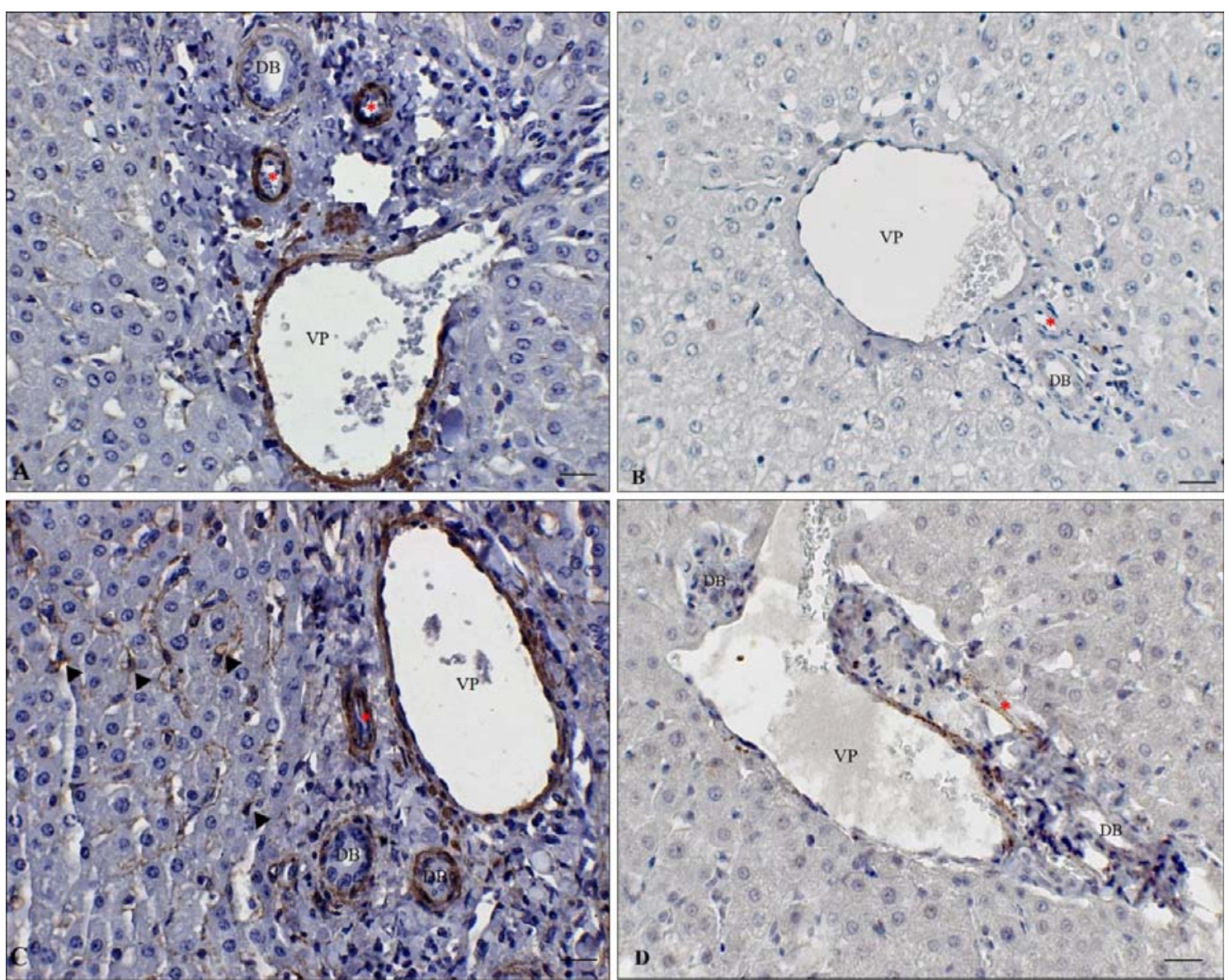

Figura 2. Imuno-histoquímica de fígado bovino condenado por fasciolose. A) Miofibroblastos em arteríolas (*), vênula portal (vp) e ductos biliares (DB), imunomarcados com o anticorpo $\alpha$-SMA, barra $14,5 \mu \mathrm{m}$. B) Região de espaço porta com arteríola (*), vênula portal (vp) (v) e ducto biliar (DB) sem imunomarcação para fibroblasto. Anticorpo TE7, barra 14,5 $\mu \mathrm{m}$. C) Células estreladas hepáticas $\alpha$-SMA positivas (cabeça de seta) com distribuição predominante no parênquima, fibrose grau 1. Barra $6,4 \mu \mathrm{m}$. D) Miofibroblastos imunomarcados com elastina circundando de vênula portal (v) e arteríolas (*) e ductos biliares (DB). Anticorpo antielastina, barra $14,5 \mu \mathrm{m}$.

No presente estudo, não houve associação entre a quantidade de $\mathrm{CEH}$ e o grau de fibrose (1, 2 e 3$)$ no lobo hepático direito $(\rho=-0,20 ; P=0,09)$ nem no lobo hepático esquerdo $(\rho=0,02 ; \mathrm{P}=0,85)$. Por outro lado, houve uma correlação negativa e significativa entre os graus de fibrose $(\rho=-0,44$; $\mathrm{P}<0,0001)$ e a quantidade de $\mathrm{CEH}(\rho=-0,61$; $\mathrm{P}<0,0001)$, contrapondo-se ao que se observa em seres humanos (Carpino et al., 2005; Chu et al., 2008) e em ratos, em que há aumento das $\mathrm{CEH}$ durante a progressão da fibrose hepática (Cassiman et al., 2002). Essa correlação negativa pode estar relacionada com a apoptose das $\mathrm{CEH}$ ativadas (Issa et al., 2001), pois, segundo Beaussier et al. (2007), essas células são mais susceptíveis à apoptose espontânea.

Ao se avaliar a quantidade de células imunomarcadas nos espaços porta, verificou-se aumento no número das estruturas portais, bem como aumento no número de camadas circundando cada uma dessas estruturas, arteríolas (AP), vênulas (VP) e ductos biliares (DB) (Fig. 3). Mas não houve influência de qualquer estrutura do espaço porta, em particular, sobre o grau de fibrose hepática $(\mathrm{P}>0,05)$. 


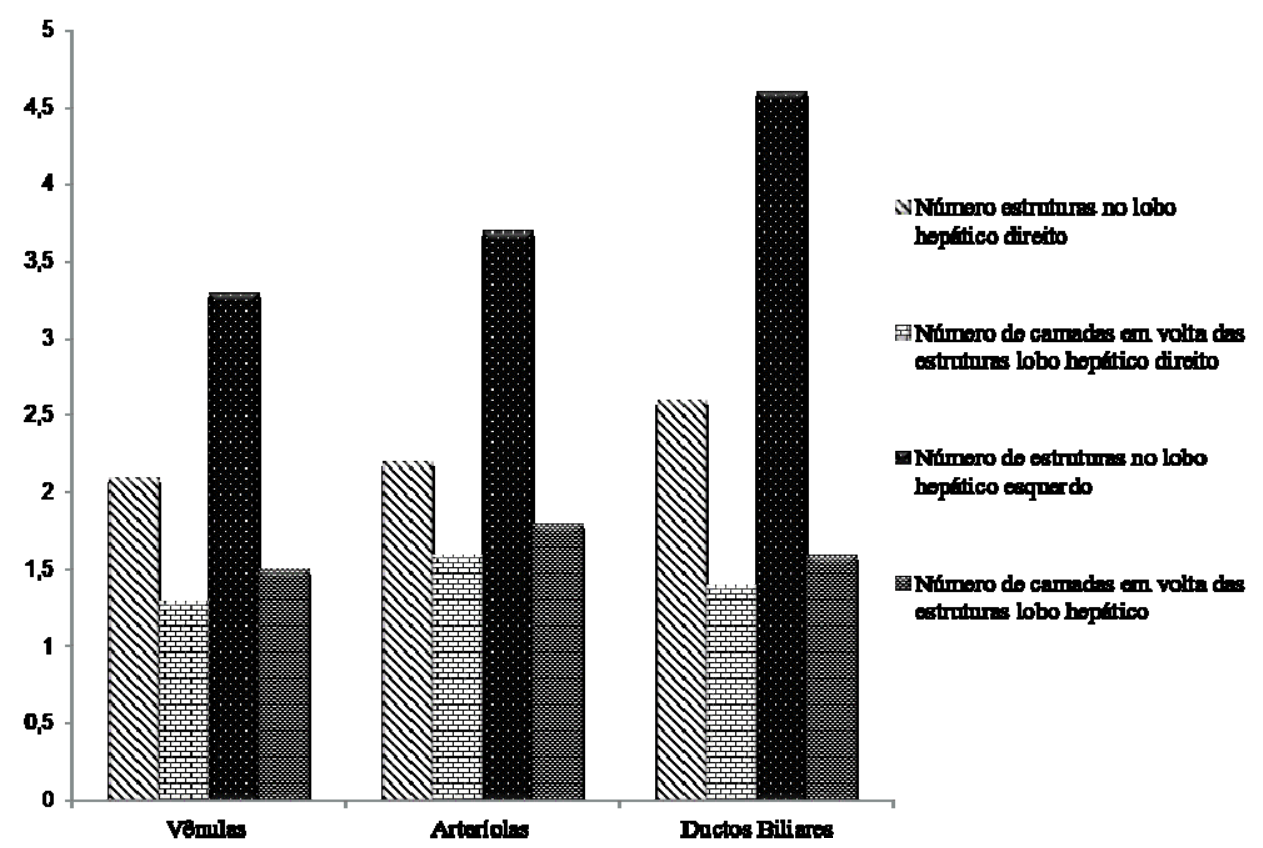

Figura 3. Valores médios da quantidade de estruturas (vênulas, arteríolas e ductos biliares) e do número de camadas de miofibroblastos circundando cada estrutura por lobo hepático em fígados bovinos infectados por $F$. hepatica.

Diferentemente do observado neste trabalho, Kinnman e Housset (2002), Uchio et al. (2002) e Magness et al. (2004) verificaram aumento de MF circundando os vasos portais e os ductos biliares à medida que a fibrose hepática progride. Libbrecht et al. (2002) e Lemoinne et al. (2015) relatam que as células residentes na parede da artéria portal contribuem para reparar os danos no espaço porta, assim essas células contribuem efetivamente para a fibrogênese hepática. Dados semelhantes foram verificados nesses estudos.

\section{CONCLUSÃO}

As CEH e os MFs desempenham um papel importante na fibrogênese de fígados bovinos frente à infecção por $F$. hepatica e estão distribuídos no parênquima hepático e no EP, respectivamente, em qualquer grau de fibrose.

\section{AGRADECIMENTOS}

Ao suporte financeiro da Coordenação de Aperfeiçoamento de Pessoal de Nível Superior (Capes), ao Programa Nacional de Cooperação Acadêmica (Procad) e à Fundação de Amparo à Pesquisa do Estado do Espírito Santo (Fapes), pelas bolsas concedidas.

\section{REFERÊNCIAS}

ALVES, D.P.; CARNEIRO, M.B.; MARTINS, I.V.F. et al. Distribution and factors associated with Fasciola hepatica infection in cattle in the south of Espírito Santo state, Brazil. J. Venom. Anim. Toxins Incl. Trop. Dis., v.17, p.271-276, 2011. Available in: $<$ http://dx.doi.org/10.1590/S167891992011000300006>. Accessed in: 13 nov. 2013.

ASAHINA, K.; TSAI, L.Y.; LI, P. et al. Mesenchymal origin of hepatic stellate cells, submesothelial cells, and perivascular mesenchymal cells during mouse liver development. Hepatology, v.49, p.998-1011, 2009. Available in: <http://onlinelibrary. wiley.com/doi/10.1002/hep.23003/pdf $>$.

Accessed in: 13 nov. 2013.

BATALLER, R.; BRENNER, D.A. Liver fibrosis. J. Clin. Invest., v.115, p.209-218, 2005. Available in: <http://www.jci.org/articles/ view/24282/pdf $>$. Accessed in:13 nov. 2013. 
BEAUSSIER, M.; WENDUM, D.; SCHIFFER, E. et al. Prominent contribution of portal mesenchymal cells to liver fibrosis in ischemic and obstructive cholestatic injuries. Lab. Investig., v.87, p.292-303, 2007.

CARPINO, G.; MORINI, S.; CORRADINI, S.G. et al. Alpha-SMA expression in hepatic stellate cells and quantitative analysis of hepatic fibrosis in cirrhosis and in recurrent chronic hepatitis after liver transplantation. Dig. Liver Dis., v.37, p.349-356, 2005. Available in: $<$ http://dx.doi.org/10.1016/j.dld.2004.11.009>.

Accessed in: 13 nov.2013

CASSIMAN, D.; LIBBRECHT, L.; DESMET, V. et al. Hepatic stellate cell/myofibroblast subpopulations in fibrotic human and rat livers. J. Hepatol., v.36, p.200-209, 2002.

CHU, C.M.; SHYU, W.C.; LIAW, Y.F. Comparative studies on expression of alpha smooth muscle actin in hepatic stellate cells in chronic hepatitis B and C. Dig. Dis. Sci., v.53, p.1364-1369, 2008.

ESPINOZA, J.R.; TERASHIMA, A.; HERRERA-VELIT, P.; MARCOS, L. Fasciolosis humana y animal en el perú: impacto en la economía de las zonas endêmicas. Rev. Peru Med. Exp. Salud Publica, v.27, p.604-12, 2010.

FRIEDMAN, S.L. Hepatic stellate cells: protean, multifunctional, and enigmatic cells of the liver. Physiol. Rev., v.88, p.125-172, 2008.

GOLBAR, H.M.; IZAWA, T.; JUNIANTITO, V. et al. Immunohistochemical characterization of macrophages and myofibroblasts in fibrotic liver lesions due to Fasciola infection in cattle. J. Vet. Med. Sci., v.75, p.857-865, 2013.

GOMES, A.T.; CUNHA, L.M.; BASTOS, C.G. et al. Capillaria hepatica in rats: focal parasitic hepatic lesions and septal fibrosis run independent courses. Mem. Inst. Oswaldo Cruz, v.101, p.895-898, 2006.

GRESSNER, AM.; WEISKIRCHEN, R. Modern pathogenetic concepts of liver fibrosis suggest stellate cells and TGF- $\beta$ as major players and therapeutic targets. J. Cell. Mol. Med., v.10, p.76-99, 2006.
ISSA, R.; WILLIAMS, E.; TRIM, N. et al. Apoptosis of hepatic stellate cells: involvement in resolution of biliary fibrosis and regulation by soluble growth factors. Gut, v.48, p.548-557, 2001.

KINNMAN, N.; HOUSSET, C. Peribiliary myofibroblasts in biliary type liver fibrosis. Front. Biosci., v.1, p.496-503, 2002.

KUKOLJ, V.; NEŠIĆ, S.; VUČIĆEVIĆ, I. Distribution of hepatic stellate cells and their role in the development of parasitic fibrosis and liver cirrhosis in domestic animals. Vet. Glasnik, v.69, p.3-11, 2015.

LEMOINNE, S.; CADORET, A.; EL MOURABIT, H. et al. Origins and functions of liver myofibroblasts. Biochim. Biophys. Acta, v.1832, p.948-954, 2013.

LEMOINNE, S.; CADORET, A.; RAUTOU, P.E. et al. Portal myofibroblasts promote vascular remodeling underlying cirrhosis formation through the release of microparticles. Hepatology, v.61, p.1041-1055, 2015.

LIBBRECHT, L.; CASSIMAN, D.; DESMET, $\mathrm{V}$;; ROSKAMS, T. The correlation between portal myofibroblasts and development of intrahepatic bile ducts and arterial branches in human liver. Liver, v.22, p.252-258, 2002.

MAGNESS, S.T.; BATALLER, R.; YANG, L.; BRENNER, D.A. A dual reporter gene transgenic mouse demonstrates heterogeneity in hepatic fibrogenic cell populations. Hepatology, v.40, p.1151-1159, 2004.

MARCOS, L.A.; MACHICADO, A.; ANDRADE, R. et al. Hepatic fibrosis and Fasciola hepatica infection in cattle. $J$. Helminthol., v.81, p.381-386, 2007.

MARCOS, L.A.; TERASHIMA. A.; YI, P. et al. Mechanisms of liver fibrosis associated with experimental Fasciola hepatica infection: roles of Fas2 proteinase and hepatic stellate cell activation. J. Parasitol., v.97, p.82-87. 2011.

MEEUSEN, E.N.T.; PIEDRAFITA, D. Exploting natural immunity to helminth parasites for the development of veterinary vaccines. Int J. Parasitol., v.33, p.1285-1290, 2003. 
OLIVEIRA, L.; SOUZA, M.M.; ANDRADE, Z. Capillaria hepatica-induced hepatic fibrosis in rats: paradoxical effect of repeated infections. Rev. Soc. Bras. Med. Trop., v.37, p.123-127, 2004.

PAROLA, M.; PINZANI, M. Hepatic wound repair. Fibrogenesis Tissue Repair, v.2, p.4-9, 2009.

RAMADORI, G.; SAILE, B. Portal tract fibrogenesis in the liver. Lab. Investig., v.84, p.153-159, 2004.

SAFADI, R.; FRIEDMAN, S.L. Hepatic fibrosis role of hepatic stellate cell activation. Medscape J. Med., v.4, p.27, 2002.

SHIRAI, W.; SATO, T.; SHIBUYA, H. et al. Anatomicopathological study of vascular and biliary system using cast samples of Fasciolainfected bovine livers. J. Vet. Med. A Physiol. Pathol. Clin. Med., v.53, p.239-245, 2006.
TESSELE, B.; BRUM, J.S.; BARROS, C.S.L. Lesões parasitárias encontradas em bovinos abatidos para consumo humano. Pesqui. Vet. Bras., v.33, p.873-889, 2013.

TRIVILIN, L.O.; SOUSA, D.R.; NUNES, L.C. et al. Histopathology aspects and fibrosis evaluation of bovine naturally infected livers by Fasciola hepatica. Arch. Vet. Sci., v.19, p.61-69, 2014.

UCHIO, K.; TUCHWEBER, B.; MANABE, N. et al. Cellular retinol-binding protein-1 expression and modulation during in vivo and in vitro myofibroblastic differentiation of rat hepatic stellate cells and portal fibroblasts. $L a b$. Investig., v.82, p.619-628, 2002. 